\title{
Preliminary testing of innovative ventilation fittings
}

\author{
Bogdan Derbiszewski ${ }^{1,}{ }^{*}$, Michat Głogowski ${ }^{2}$, Lukasz Szymański ${ }^{1}$, Tomasz Olejnik ${ }^{3}$, \\ and Andrzej Obraniak ${ }^{2}$ \\ ${ }^{1}$ The President Stanisław Wojciechowski State University of Applied Sciences in Kalisz, 62-800 \\ Kalisz, ul. Nowy Świat 4, Poland \\ ${ }^{2}$ Faculty of Process and Environmental Engineering, Lodz University of Technology, Wolczanska \\ 213, 90-924 Lodz, PL \\ ${ }^{3}$ Faculty of Biotechnology and Food Sciences, Lodz University of Technology, Wolczanska 173, \\ 90-924 Lodz, PL
}

\begin{abstract}
The article primarily presents a schematic idea of the operation of innovative ventilation shapes with adjustable performance. Then, it was pre-verified by measuring static pressure on the walls of ordinary fittings and innovative T-type fittings. The presented fittings have features that allow for very precise control of the performance of ventilation streams in various configurations. The most important diagrams in the article show that there are simple methods for distributing air streams, even in mutually perpendicular channels leading to minimized flow losses. The presented results of comparative tests carried out on ordinary and innovative T-shaped fittings show very favorable tendencies which are characterized by a several-dozen-percent drop in pressure in similar measurement ranges.
\end{abstract}

\section{Introduction}

Ventilation fittings (tees, cross-pieces, elbows, etc.) are the basic elements of air distribution systems in mechanical ventilation systems [1]. They are commonly used in ventilation systems in residential buildings [2], public facilities (eg hospitals [3]) and industrial facilities [4,5].

Ventilation systems are subject to continuous expansion and modification, behind which there is a reduction of embedded energy and energy related to the use of the installation. Any system solution [6-7] leading to the reduction of the above-mentioned energy costs is expected on the ventilation systems market. The elements that reduce energy consumption related to the use include, among others, ventilation air distribution systems, i.e. ventilation ducts connected with special ventilation fittings. This type of elements depends, among others: flow resistance, noise level and heat exchange between the ventilation air and the environment.

In the article, Fig. 1 to Fig. 7, a solution based on an innovative system for controlling the performance of streams in ventilation fittings is shown, which fittings are provided in

\footnotetext{
*Corresponding author: b.derbiszewski@pwsz-kalisz.edu.pl
} 
the same way as in patent application no. P419589 [] numerical references. According to these references, we can distinguish:

1 - fence placed in the ventilation fitting,

2 - adjusting catch,

3 - ventilation fitting of a given type,

4 - ventilation air stream.

The application of additional fences in the future will completely eliminate additional throttling components which equalize ventilation flows in individual branches of the system.

\section{Purpose of the study}

The purpose of this study was to carry out tests consisting in determining the static pressure distribution on the walls of a traditional and innovative T-shaped tee.

Fig. 1 and Fig. 2 schematically show a T-shaped branching fitting with central supply, in various positions of control units with schematically marked intensity of air flows. This type of branching is particularly important in the case of limited space for the system to be installed; i.e. requiring the shortest possible ventilation ducts. But it will also work well with industrial plants where the cost of ventilation ducts is already a significant item.

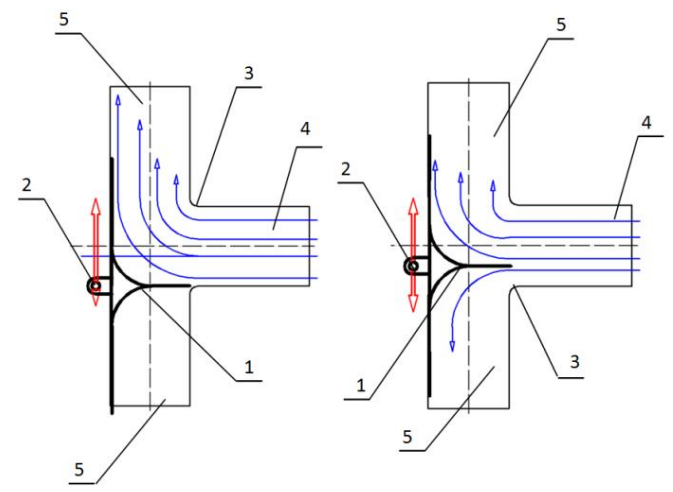

Fig. 1 Diagram of operation of a T-type fitting with central supply

Fig. 2 schematically show a T-shaped branching fitting with side power supply, in various positions of control units with schematically marked intensity of air flows. This type of supply of a T-shaped fitting can be useful in hard-to-reach places and in the cases where the ventilation ducts are clearly asymmetrical. Again, the diagram shows that in this type of branching it is possible to regulate the ventilation stream in the full range.
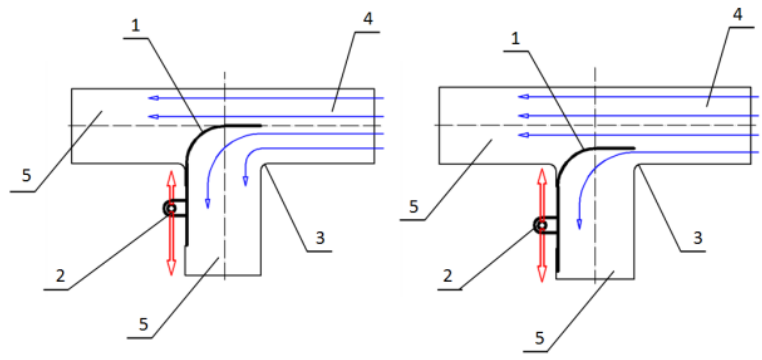

Fig. 2 Diagram of operation of a T-type fitting with side supply 
Fig. 3 and Fig. 4 schematically show a Y-shaped branching fitting with side supply, in various positions of control units with schematically marked intensity of air flows. In principle, this fitting does not require a fence at even distribution of ventilation streams, therefore its application should be considered only in the case of ventilation resistance asymmetry.
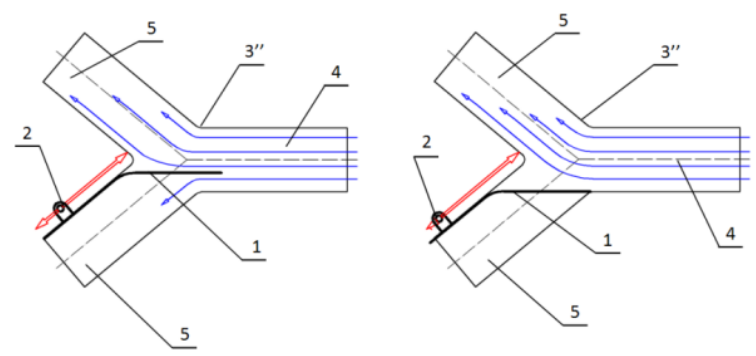

Fig. 3 Diagram of operation of a Y-type fitting with central supply
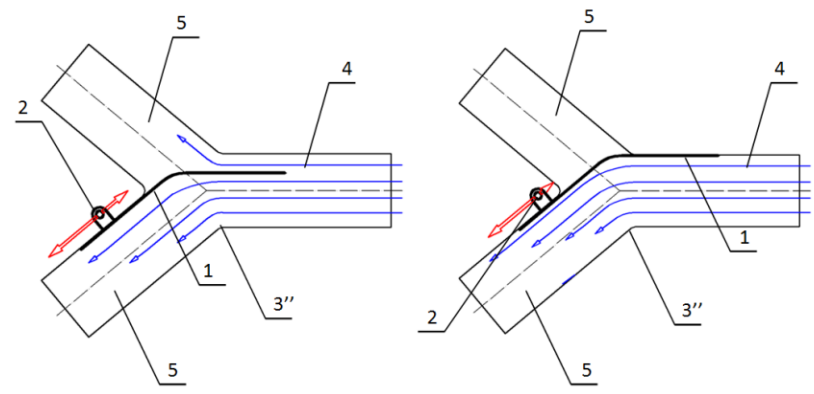

Fig. 4 Diagram of operation of a Y-type fitting with central supply

Fig. 5, Fig. 6 and Fig. 7 are schematic representation of a "+" branching fitting, i.e. a cross-shaped fitting, in various positions of the control units. This type of branching is particularly important in the case of limited space for the system to be installed; i.e. requiring the shortest possible ventilation ducts. But it will also work well with industrial plants where the cost of ventilation ducts is already a significant item.
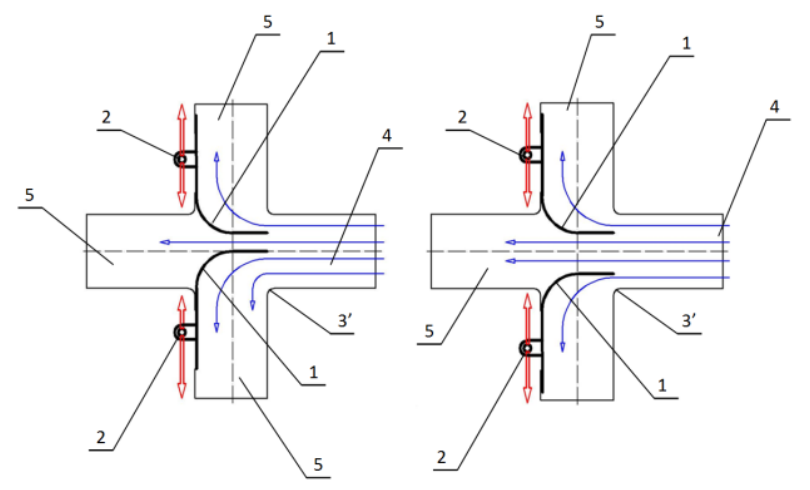

Fig. 5 Diagram of operation of a cross-shaped fitting 

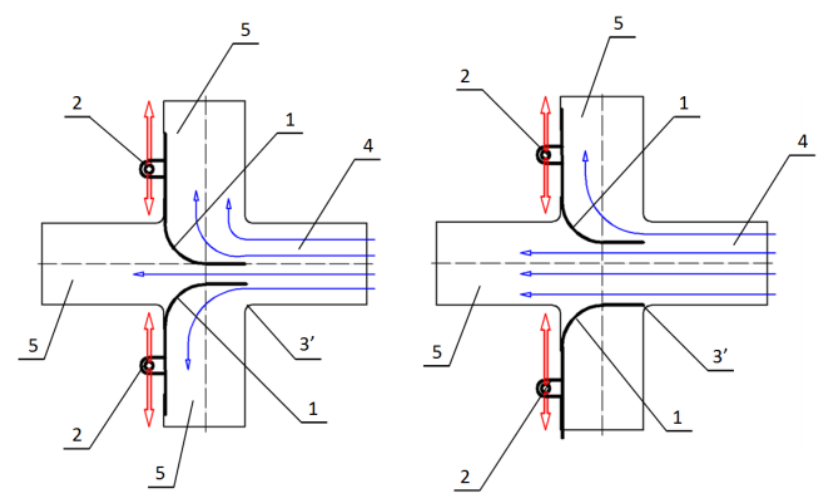

Fig. 6 Diagram of operation of a cross-shaped fitting
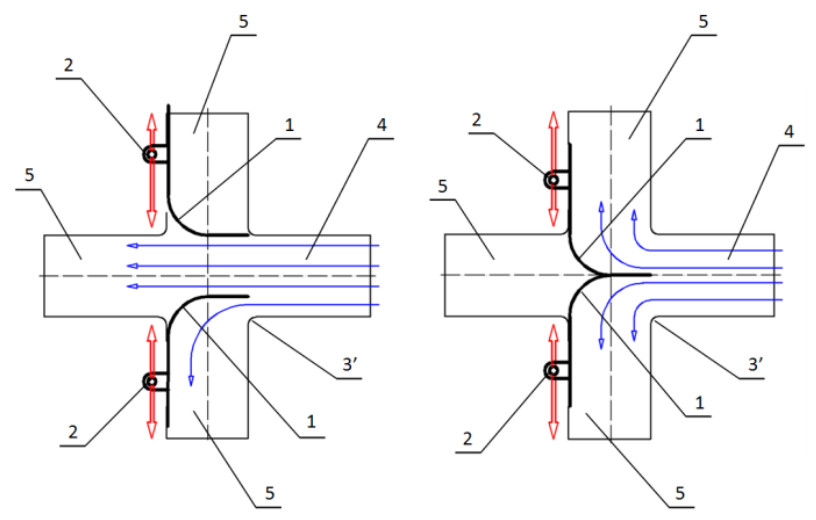

Fig. 7 Diagram of operation of a cross-shaped fitting

To sum up, from all the diagrams shown in Fig. 7, Fig. 8 and Fig. 9 - as it has been previously shown - it appears that it is possible to divide the ventilation streams very accurately even for three outflow streams, but in this case a double independent control is required with the use of two fences (2). This diagram is the last one discussed in this article, but it should be emphasized that there are definitely more such schemes which successfully implement further variants of ventilation fittings based on the shifting fence idea. To sum up, from all the diagrams shown in Fig. 1 to Fig. 9 it appears that it is possible to divide the ventilation flows very accurately for three and more outflow streams by means of shifting fences.

\section{Preliminary tests}

During the initial qualitative assessment, tests were carried out on T-type ventilation fittings equipped with a fence - where it is possible for it to make a smooth or step change in the position with a resolution of up to 30 positions, which is shown in Fig. 8. In addition, the design of the fitting made it possible to disassemble the fence, allowing for direct comparison of both types of fittings, maintaining, which is important, exactly the same geometry of the supply and outlet channels as well as the external dimensions of the fitting. The splitter was equipped with more than 30 measuring connections symmetrically arranged with respect to the symmetry planes. During measurements in various 
combinations, these connections were attached to liquid manometers and the pressure distribution in the internal walls of the tee was examined.

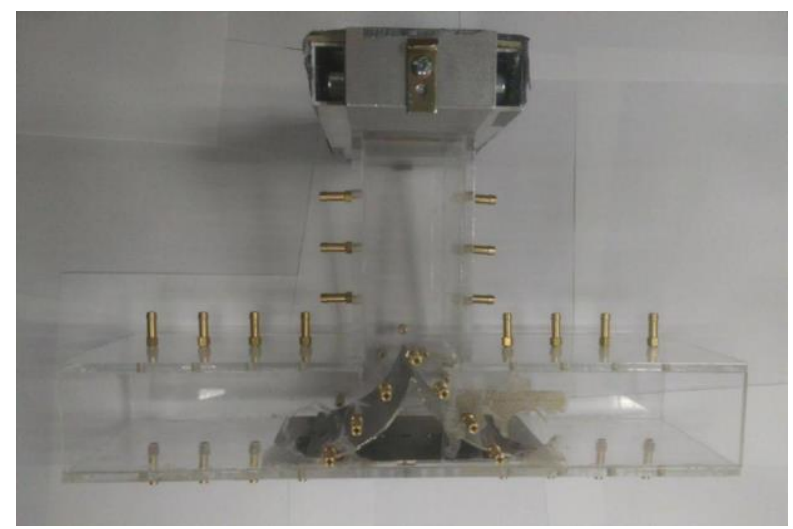

Fig. 8 Measuring T-type fitting

The pressure distribution in the base T-shaped fitting is shown in Fig. 9, and at each of the connections the average value of the static pressure difference related to atmospheric pressure is provided. Subsequently, the same tests were applied to the fitting shown in Fig. 10 with centrally located fence (2).

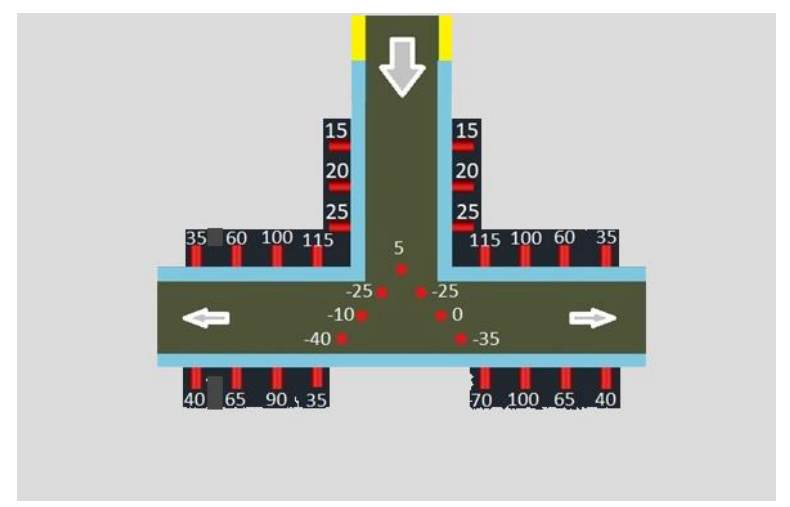

Fig. 9 Measuring T-type fitting - static pressure distribution.

The first thing that can be noticed is the occurrence of negative values, which indicate that there is no accumulation of the air stream on the wall perpendicular to the incoming stream direction. As mentioned, this was the expected effect, nevertheless the differences are impressive given a single component of the ventilation system. 


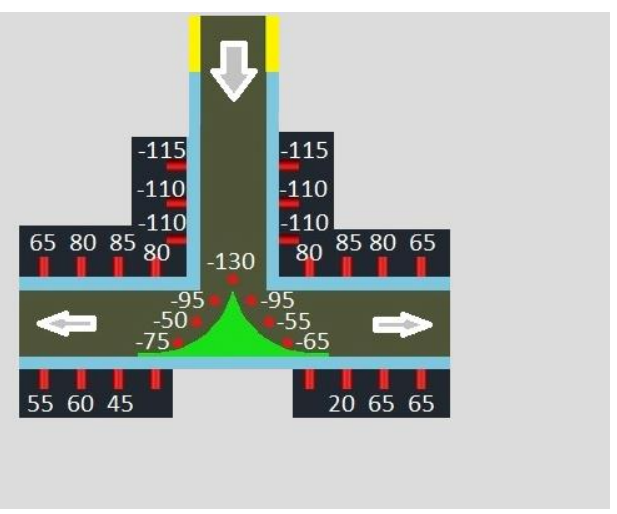

Fig. 10 Measuring T-type fitting with a centrally placed fence - static pressure distribution

Table 1 below shows with detailed measurements used to prepare diagrams with pressure change on the walls of a T-type ventilation tee. The results were obtained for the following conditions:

$\mathrm{P}_{\mathrm{a}}-1006 \mathrm{hPa}$
$\mathrm{T}_{\mathrm{a}}-22{ }^{\circ} \mathrm{C}$
$\mathrm{x}-39 \%$

Table 1.

\begin{tabular}{|c|c|c|}
\hline Distance $\mathbf{m m}$ & $\Delta \mathbf{p}_{\text {normal }} \mathbf{P a}$ & $\Delta \mathbf{p}_{\text {modified }} \mathbf{P a}$ \\
\hline-146 & 40 & 65 \\
\hline-116 & 65 & 65 \\
\hline-86 & 90 & 20 \\
\hline-56 & 35 & 0 \\
\hline-42 & -40 & -75 \\
\hline-28 & -10 & -50 \\
\hline-14 & -25 & -95 \\
\hline 0 & 5 & -130 \\
\hline 14 & -25 & -95 \\
\hline 28 & 0 & -55 \\
\hline 42 & -35 & -65 \\
\hline 56 & 70 & 0 \\
\hline 86 & 100 & 45 \\
\hline 116 & 65 & 60 \\
\hline 146 & 40 & 55 \\
\hline & & \\
\hline 66 & & \\
\hline
\end{tabular}


On the basis of the table, a diagram was prepared shown in Fig. 11 - static pressure changes on the walls of T-type tee. The diagram in Fig. 11 shows changes in the function of changes in the distance from the symmetry plane.

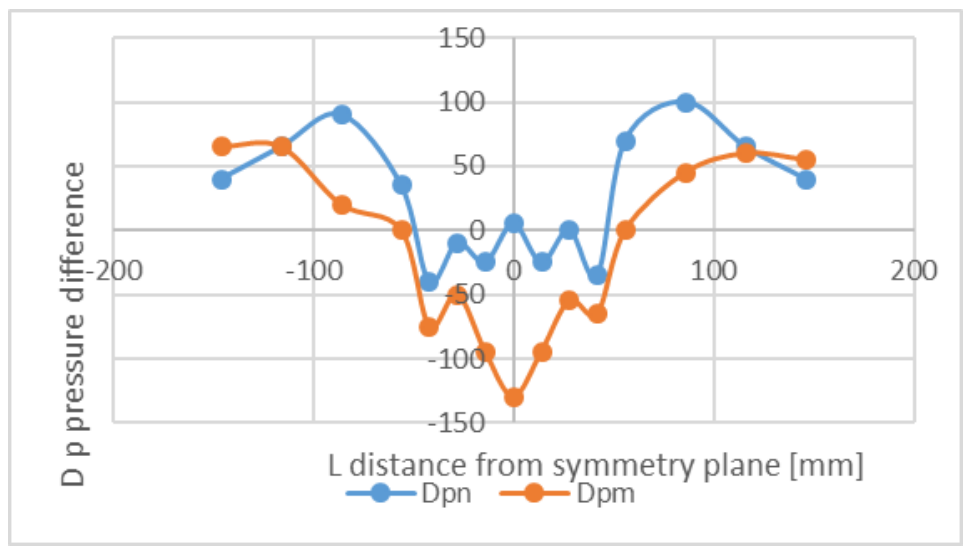

Fig. 11 Distribution of pressure on a measuring T-type fitting.

\section{Conclusions}

The analysis of the results obtained draws us to the conclusion that the use of innovative fittings, i.e. ventilation fittings equipped with shifting-adjustable fences or shifting fences with automatic adjustment, allow for very precise control of the ventilation airflow.

The results of the tests, which in the description were limited to a T-shaped fitting and the central arrangement of the fence, in all the measurements showed more than $100 \%$ reduction of the accumulation in the supply channel as compared to fittings without an internal shifting fence. Particularly noteworthy is the accuracy of the division of air streams, because in the tests we managed to achieve $2 \%$ repeatable accuracy of the symmetric distribution of air streams.

Taking into account the fact that in an average system of a single-family house there are 4 up to 6 branchings mentioned in this article, basing on this example of a systems you can expect about $5 \%$ up to $10 \%$ reduction in electricity consumption by fans of ventilation or air conditioning systems. It can be assumed that such elements as ventilation air distribution and smooth fan speed control will guarantee long-lasting and proper performance. In the case of automatic control, there is the possibility of continuous monitoring of the air stream, which in turn leads to a better use of the power supplied.

\section{References}

1. Zhang Lin T. T. Chow K. F. Fong Qiuwang Wang YingL International Journal of Refrigeration 28(2):276-287 (2005)

2. Zhang Lin, T.T. Chow, K.F. Fong, C.F. Tsang, Qiuwang Wang International Journal of Refrigeration 28(2):288-305 (2005)

3. Rae Jean Hemway, Catherine Christman, Jeffrey Perlman Archives of Disease in Childhood - Fetal and Neonatal Edition 98(1) (2012)

4. Chia-Hsiang Lai Yen-Ping Peng Journal of Environmental Sciences Volume 23,2011,941-948 (2012) 
5. Oh-Hyun Kwon, Min-Hwi Kim, An-Seop Choi, Jae-Weon Jeong, Energy and Buildings 57, 346-353 (2013)

6. Moo-Hyun Kim Ji-Hyeon Hwang Energy and Buildings 41(6):579-586 (2009)

7. Karłowski J., Myczko R., Kołodziejczyk T., Kuczyński T. Problemy Inżynierii Rolniczej 16(1) 151-158 (2008)

8. Zgłoszeniu patentowe w Polsce nr $\mathbf{P 4 1 9 5 8 9}$ 